\title{
Electrodeposition of Alloys of Phosphorus with Nickel or Cobalt
}

\author{
By Abner Brenner, Dwight E. Couch, and Eugenia Kellogg Williams
}

\begin{abstract}
Alloys containing nickel or cobalt and as much as 15 percent of phosphorus have been electrodeposited from solutions containing phosphites. The alloys are hard and may be further hardened by heat-treating at $400^{\circ} \mathrm{C}$. The high-phosphorus nickel alloy is more resistant to attack by hydrochloric acid than pure nickel deposits. The high-phosphorus alloys are bright as deposited, but their reflectivities are lower than those of buffed coatings of pure nickel.
\end{abstract}

\section{Introduction}

Deposits of cobalt and nickel have been produced by chemical reduction [1] ${ }^{1}$ of solutions of their metal salts with hypophosphites at elevated temperatures. These deposits contained several percent of phosphorus and were harder than ordinary electrodeposits of nickel and cobalt. They increased in hardness when heat-treated at $400^{\circ} \mathrm{C}$ and were not appreciably softened by annealing at $600^{\circ} \mathrm{C}$. The nickel-phosphorus deposit is also of interest because it is semibright when deposited from an alkaline solution. The properties of the deposits obtained by chemical reduction in the "electroless" process were of sufficient interest to lead to an attempt to find more satisfactory conditions of deposition. As the electroless process is uneconomical, produces deposits at a slow rate, and does not permit control of the composition of the deposits, attention was directed toward a study of the electrodeposition of metals with phosphorus.

Alloys of nickel or cobalt containing as much as 15 percent of phosphorus were obtained by electrodeposition from acid solutions containing phosphites. These alloys are of theoretical interest because many of them contain over 50 percent of the metal phosphide, and yet in all of their properties they are decidedly metallic. The electrodeposition process is also of theoretical interest because phosphorus is nonmetallic and does not conduct current, and in this process is deposited from an anion.

\footnotetext{
1 Figures in brackets indicate the literature references at the end of this paper.
}

The effect of phosphites and hypophosphites in other plating baths was examined qualitatively, but as no obviously interesting results were obtained, no analyses were made of the deposits. The baths investigated included acid copper, acid zinc, and hot ferrous chloride. The addition of phosphorus compounds produced a black or rough deposit in the last bath, and had little effect on the others except to make the deposits rough. Similarly, no important result was obtained with a cyanide silver bath, a cyanide zinc bath, or an alkaline tin bath. The deposit from an alkaline cobalt-tungsten bath to which phosphite had been added did not contain any phosphorus.

In our initial efforts to electrodeposit the phosphorus alloys the conditions were similar to those employed in the electroless plating process, but no alloys were obtained. Later it was found that the conditions for the electrodeposition of the phosphorus alloys are quite different from those required for the electroless process. This is shown by the following contrasts: (1) Electroless plating is readily conducted with ammoniacal solutions, but phosphorus alloys of cobalt and nickel cannot be electrodeposited from such solutions; (2) cobaltphosphorus alloys cannot be obtained from an acid solution by the electroless process but are readily obtained by electrodeposition; (3) phosphites are the most satisfactory source of phosphorus for the electrodeposition process, but they produce no reduction to metal in the electroless plating process. 


\section{Composition of Plating Baths and Con- ditions of Plating}

The best deposits were obtained from ordinary nickel or cobalt baths to which phosphoric and phosphorus acids had been added. The favorable $\mathrm{pH}$ of the baths was between 0.5 and 2.0 , depending upon their compositions. Table 1 gives the composition of several satisfactory baths. Deposits may be obtained also from acid solutions containing only the metal phosphite. (Solution $\mathrm{Ni}-\mathrm{P}$ and $\mathrm{Co}-\mathrm{P}$, table 1.)

The plating solutions were prepared by first making up an ordinary plating solution, about 1 molar in metal. A Watts bath may be used as the basis for the nickel-phosphorus bath and a cobalt chloride solution for the cobalt-phosphorus bath. The phosphoric and phosphorus acids were introduced into the bath in the form of a stock solution prepared by partially neutralizing the acids to a $\mathrm{pH}$ of about 1.0 with a basic carbonate of the desired metal. This stock solution contained the metals as the acid salts along with free acid. When a low concentration of phosphites was required, as in bath $\mathrm{Co}-\mathrm{F}$, the acid could be added directly to the bath. With the cobalt bath, Co-F, pitting is liable to occur, and the addition of a wetting agent may be necessary for the production of thick deposits. In electroforming deposits about $8 \mathrm{~mm}(0.3 \mathrm{in}$.) thick from the latter bath it was also found expedient to add saccharin, $5 \mathrm{~g} /$ liter, to reduce the stress in the deposit.

In this study, a number of different bath compositions were tried and discarded. The following discussion summarizes the materials tried and the reasons why they were accepted or rejected.

In the earlier stages of this study, baths containing hypophosphites were tried and were found to yield deposits that contained phosphorus. Some of these deposits were quite bright. However, they were unsound and frequently were so highly stressed that they developed visible networks of cracks. Another reason for abandoning work with the hypophosphites was that they were not stable in hot solutions. Phosphorus acid, on the other hand, is apparently stable in hot solutions. It is readily available (in commerce), usually as a 30-percent solution, but can be obtained in solutions of higher concentration and also as a crystalline solid. The price is about $\$ 1.00$ per pound of anhydrous acid.

One of the most important considerations in the successful electrodeposition of the phosphorus alloys is the $\mathrm{pH}$ of the plating solutions. If the $\mathrm{pH}$ is more than several tenths above an optimum value, the deposits are likely to be discolored, stressed, or unsound; if the $\mathrm{pH}$ is too low, the cathode current efficiency is very low.

Because of the necessity of controlling the $\mathrm{pH}$ within narrow limits, it soon became apparent that buffers would simplify the control of the bath. A number of acids were tried as buffers, among them organic acids such as acetic, formic, hydroxyacetic, malic, citric, gluconic, and tartaric; and inorganic acids such as boric and phosphoric acids. These acids had specific effects on the quality of the deposits. For example, formic, acetic, and hydroxyacetic acids yielded good deposits from a cobalt-phosphorus plating bath, whereas citric, malic, and gluconic acids yielded highly stressed deposits. From a nickel bath, containing 60 $\mathrm{g} /$ liter of hydroxyacetic or citric acid, the deposits were fairly satisfactory when the $\mathrm{pH}$ of the bath was kept below 1. However, these deposits were found to warp and blister when they were heattreated at $600^{\circ} \mathrm{C}$. This did not occur if phosphoric acid was used as the buffering agent in the bath and, in general, this acid yielded better results than the organic buffers. In the presence of some of the organic acids in the nickel bath-tartaric, glycine, and aspartic acids-very poor deposits were obtained.

In the earlier work it was found that metal salts, such as chloride, sulfate, and fluoborate, did not yield equally satisfactory deposits. Some of these differences might have been eliminated if a satisfactory buffer such as phosphoric acid had been used initially. As an example of the differences that were observed, a solution for deposition of cobalt-phosphorus alloy, which was made up with sulfate and no buffering agent, had a cathode current efficiency of only 10 to 20 percent, as compar \& with about 80 percent for a similar bath made up with cobalt chloride. In developing the nickel-phosphorus bath, the sulfate was found to be more satisfactory than the chloride. Fluoborates offered no advantages over the sulfate or chloride. 


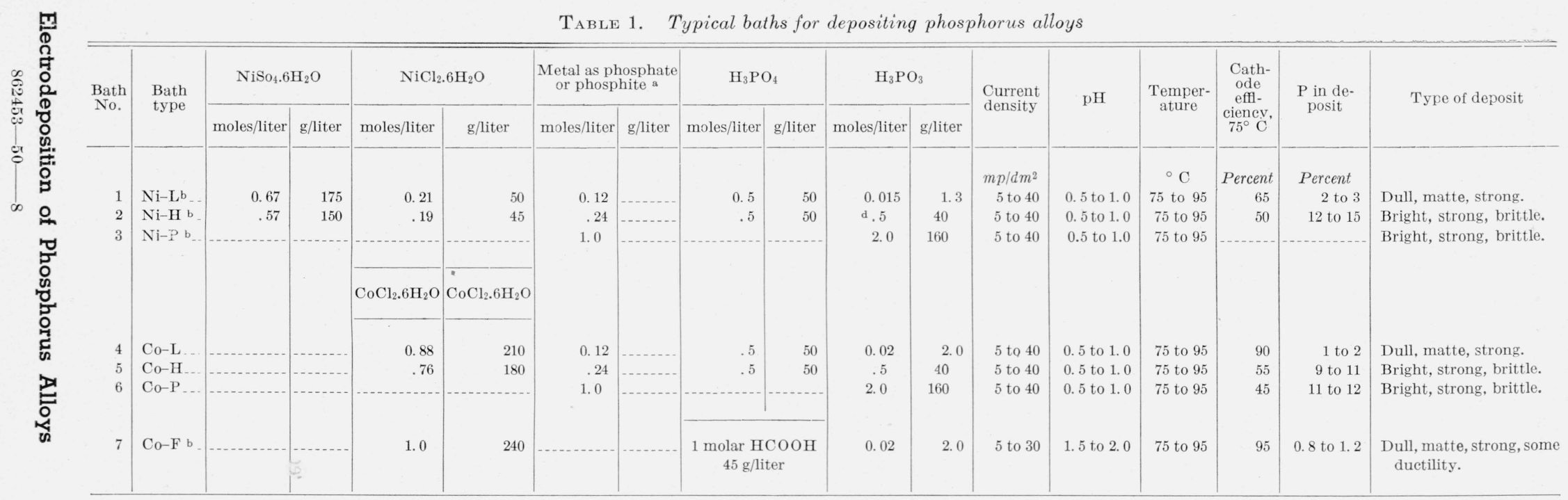

a A solution of phosphoric acid and phosphorus acid was partially neutralized with metal carbonate. About $15 \mathrm{~g}$ of metal carbonate (this is approximately $7.5 \mathrm{~g}$ metal) is required to neutralize $50 \mathrm{gc}$ of phosphoric acid of $40 \mathrm{gd}$ of phosphorus acid to $\mathrm{pH}$ of 0.5 to 1.0. All of the above baths were prepared so that the total metal concentration was about $1 \mathrm{molar}$ (60 $\mathrm{g} / \mathrm{liter}$ ).

b The letters "L" and "H" refer to phosphate-phosphite baths that produce deposits of low- and high-phosphorus content, respectively; "P" refers to baths containing no anion other than phosphite; "F" refers to a bath containing formate. Hydroxyacetic acid may be substituted for the formic acid in this bath in concentrations of 50 to $60 \mathrm{~g} /$ liter.

- Equivalent to $35 \mathrm{ml}$ of the $85 \%$ phosphoric acid.

d Equivalent to $115 \mathrm{ml}$ of the $30 \%$ phosphorous acid. 
Nickel or cobalt anodes were used in the baths, and they corroded uniformly. As the current efficiency of solution of the anode was probably 100 percent, the metal concentration in the baths tended to increase.

\section{Examination of Deposits}

Alloy coatings from 0.05 to $0.5 \mathrm{~mm}$ thick $(0.002$ to 0.02 in.) were deposited upon copper tubes about $5 \mathrm{~mm}(3 / 16$ in. $)$ in diameter. The test for the soundness of the deposit was to dissolve the copper tube with a polysulfide solution and note whether the alloy tube held together. If it did, it was further qualitatively tested for strength by crushing it with a pair of pliers. Observations were also made of the ductility of the deposit by noting whether the tube of alloy or fragments of it would take a permanent set upon bending. Specimens of the sound deposits were heated at various temperatures, and similar tests for strength and ductility were made again. On the basis of these qualitative tests, a decision was made as to whether the solution under investigation should be studied further or discarded.

Besides the qualitative examination of the physical properties of the deposits, their hardnesses were measured with a microhardness tester and their electrical resistivities were determined. These measurements were made on deposits as removed from the bath and on those which had been subjected to various heat treatments.

The procedure was as follows. A $10-$ to $15-\mathrm{cm}$ length of copper tubing was plated with the alloy, then cut into several small sections and the copper stripped out. The hardness of the alloy as deposited was measured. Other sections from the same tube were heated to $400^{\circ}, 600^{\circ}$, and $800^{\circ} \mathrm{C}$, then tested after cooling. The resistivity was measured on the alloy as deposited. The measurements were repeated on the same sample after heating to $400^{\circ}, 600^{\circ}$, and $800^{\circ} \mathrm{C}$. A few measurements of reflectivity and of tensile strength were also made. The phosphorus content of the alloys was determined gravimetrically by the phosphomolybdate method. The heat treatments of the alloys did not reduce their content of phosphorus. The corrosion resistance of the deposits to acids and to the salt spray was also determined.

\section{Effect of Bath Composition and Con- ditions of Plating Upon the Deposits}

Because the most satisfactory baths were evolved gradually in the course of the investigation, much of the data on the effect of operating conditions on the character of the deposits was determined for baths that do not represent the best composition. However, as the compositions and properties of the deposits from the different baths were similar, it was not necessary to repeat this work with those baths finally selected as the best.

\section{Concentration of Phosphite}

Figure 1 shows how the phosphorus content of the cobalt and nickel deposits varied with the concentration of phosphorous acid. For a given concentration of the acid, more phosphorus was codeposited with the nickel than with the cobalt, particularly in the baths that contained low concentrations of phosphite. The dotted line, 4, in the graph represents alloys having the same ratio of phosphorus to nickel or cobalt as exists in the solution. The nickel-phosphorus alloy (curve 1) from the baths containing less phosphorous acid than $10 \mathrm{~g}$ /liter had a higher ratio of phosphorus to metal than existed in the bath. Accordingly, phosphorus seems to be the more readily deposited element under these conditions.

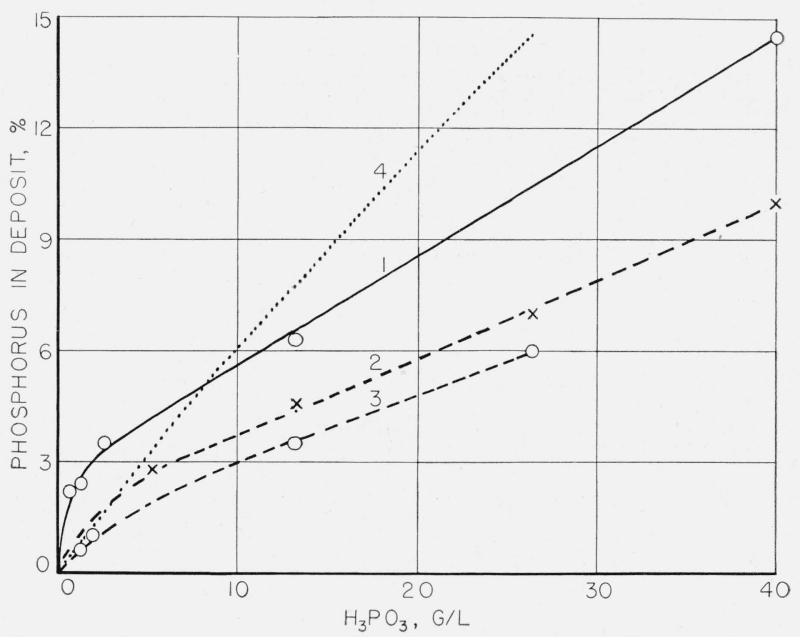

FIGURE 1. Effect of concentration of phosphorus acid in bath on the percentage of phosphorus in deposit.

Both operated at $75^{\circ} \mathrm{C}$ and $10 \mathrm{amp} / \mathrm{dm}^{2}$.

1 , Deposits from phosphorus-nickel bath with increasing amounts of phosphorus acid; 2, deposits from phosphorus-cobalt bath with increasing amounts of phosphorus acid; 3, deposits from Co-F type bath with increasing amounts of phosphorus acid; 4, line represents alloys having the same value of $\mathrm{P} /($ metal $+\mathrm{P})$ as the bath. 


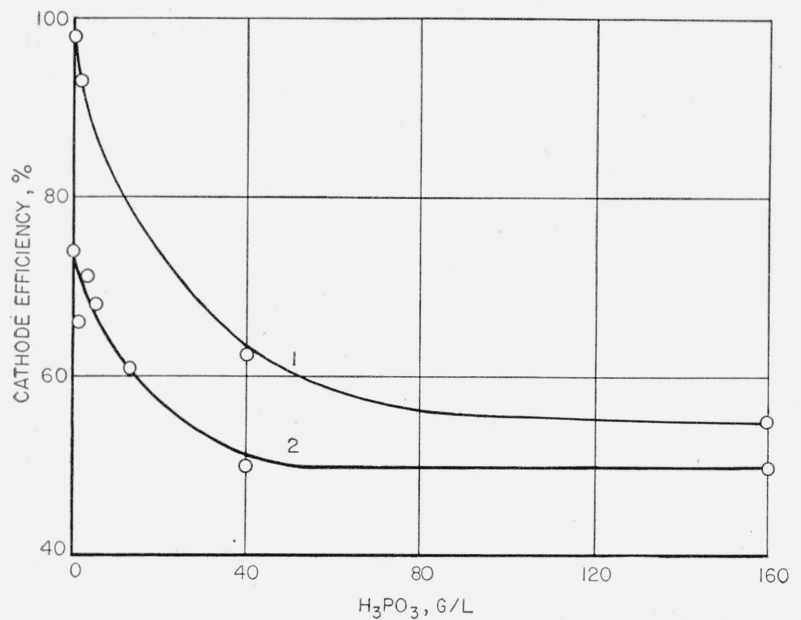

FIGURE 2. Effect of concentration of phosphorus acid on cathode current efficiency at $75^{\circ} \mathrm{C}$.

1, Cobalt-phosphorus baths; 2, nickel-phosphorus baths.

The maximum amount of phosphorus obtained in the nickel deposit was about 15 percent and in the cobalt deposit about 10 percent. No attempts were made to determine the maximum amount of phosphorus that could be introduced into the deposits. It is likely that higher ratios of phosphite to metal in the baths would give deposits higher in phosphorus.

The cathode current efficiency of deposition from the nickel bath decreased markedly as the content of phosphite in the bath was increased. This is shown by the curves in figure 2 and by the position of the curves in figure 3 .

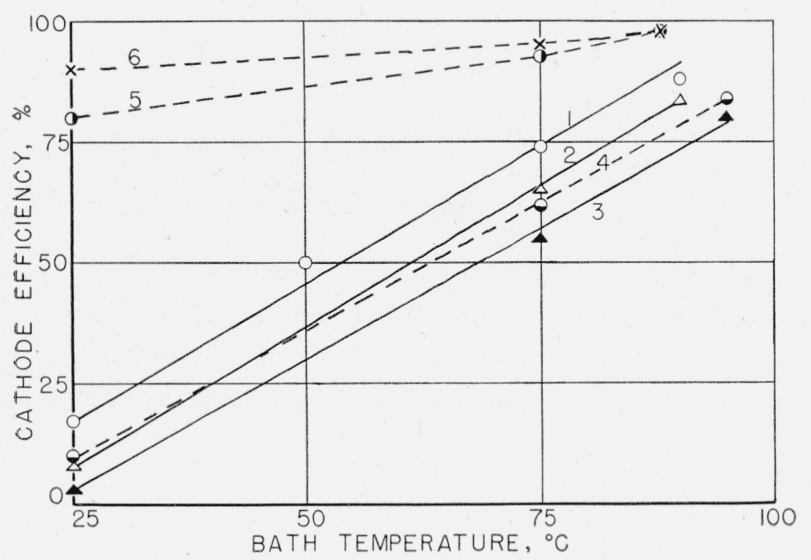

Figure 3. Effect of temperature on the cathode current efficiency of phosphorus-nickel and-cobalt baths.

1, Ni-L bath, but containing no phosphorus acid; 2, bath Ni-L; 3, bath Ni-H; 4, bath Co-H; 5, bath Co-L; 6, bath Co-F.

\section{2. $\mathrm{pH}$ of Bath}

The importance of $\mathrm{pH}$ and the general considerations that led to the operation of the cobalt and nickel baths at low $\mathrm{pH}$ have already been discussed in the introductory section. If the $\mathrm{pH}$ of a cobalt bath were too high and no buffers were present, basic material was deposited upon the cathode. In some instances, smooth deposits of a pink cobalt compound formed upon the cathode to a thickness of several tenths of a millimeter, that is, much faster than a metal coating of equal thickness could be deposited. Frequently the basic material was firm enough to be removed from the copper cathode in the form of a tube.

The necessity of operating the phosphorus alloy baths at a low $\mathrm{pH}$ of 0.5 to 2.0 was not anticipated, as the electroless plating baths operate at a relatively high $\mathrm{pH}$. Furthermore, experiments on the addition of alkali to phosphorus alloy baths indicated that precipitation did not occur until the $\mathrm{pH}$ reached 4 . to 5 in the low phosphorus bath and 3 to 3.5 in the high phosphorus bath. Thus, the alloy baths are operated at $2.5 \mathrm{pH}$ units below the precipitation point of the bath. Apparently, a low $\mathrm{pH}$ is necessary for the successful electroreduction of the phosphite, quite apart from the function of $\mathrm{pH}$ in preventing precipitation of basic compounds at the cathode.

The $\mathrm{pH}$ of the bath within the operable range does not have any appreciable effect upon the content of phosphorus in the deposits. The main effects of $\mathrm{pH}$ are on the cathode efficiency and on the soundness of the deposits. The $\mathrm{pH}$ of the high phosphite baths, $\mathrm{Ni}-\mathrm{H}$ and $\mathrm{Co}-\mathrm{H}$, is more critical than that of the low phosphite baths and must be kept between 0.5 to 1.0 . If the $\mathrm{pH}$ is lower, the cathode efficiency markedly decreases. If the $\mathrm{pH}$ is much above 1 , it is difficult to obtain uniformly bright deposits.

\section{Temperature}

Temperature is one of the most important variables in plating the phosphorus alloys. The deposits obtained at room temperature were stressed and unsound. The low mechanical strength of the deposits obtained at room temperature was apparent only after the basis metal was dissolved; otherwise the deposits appeared quite satisfactory. Most of the plating in this investigation was done at $75^{\circ} \mathrm{C}$. 
The operation of the cobalt bath was not as sensitive to temperature as that of the nickel bath. If the alloy baths were operated at room temperature instead of $75^{\circ} \mathrm{C}$, the cathode current efficiency of the low phosphorus-cobalt baths dropped only slightly, but the cathode efficiency of the corresponding nickel bath became very low. The high phosphorus-cobalt $(\mathrm{Co}-\mathrm{H})$ baths had much lower efficiencies at room temperature than at $75^{\circ}$ C. However, they produced deposits at lower temperature and at lower $\mathrm{pH}$ than the corresponding nickel bath. If the nickel bath contained much phosphite, at room temperature the efficiency was only a few percent, and in some cases all that was obtained upon the cathode was a black coloration. Figure 3 shows how the cathode current efficiency of alloy deposition changes with the concentration of phosphite and the temperature. The cathode current efficiencies were based upon the composition of the deposit. The phosphorus was assumed to have been reduced from a valence of three.

\section{Agitation}

Agitation of the bath did not seem to have any value in improving the appearance or physical properties of the deposits. It was resorted to only to prevent stratification of the solution.

\section{Current Density}

The deposits of nickel- or cobalt-phosphorus did not vary materially in appearance or physical properties when the current density was varied over a wide range. At $75^{\circ} \mathrm{C}$, deposits could be produced at current densities ranging from 5 to $30 \mathrm{amp} / \mathrm{dm}^{2}$, but when the current density was below $5 \mathrm{amp} / \mathrm{dm}^{2}$, sometimes the deposit did not completely coat the basis metal. The content of phosphorus in the deposits plated from the low phosphorus baths did not vary appreciably with current density. The deposits from the high phosphorus-nickel bath, Ni-H, showed a decrease in content of phosphorus as the current density was raised. This is illustrated in figure 4.

The cathode current efficiency of deposition of neither the cobalt nor nickel alloys varied appreciably with variations in current density. Figure 5 shows data for the deposition of nickel-phosphorus alloys.

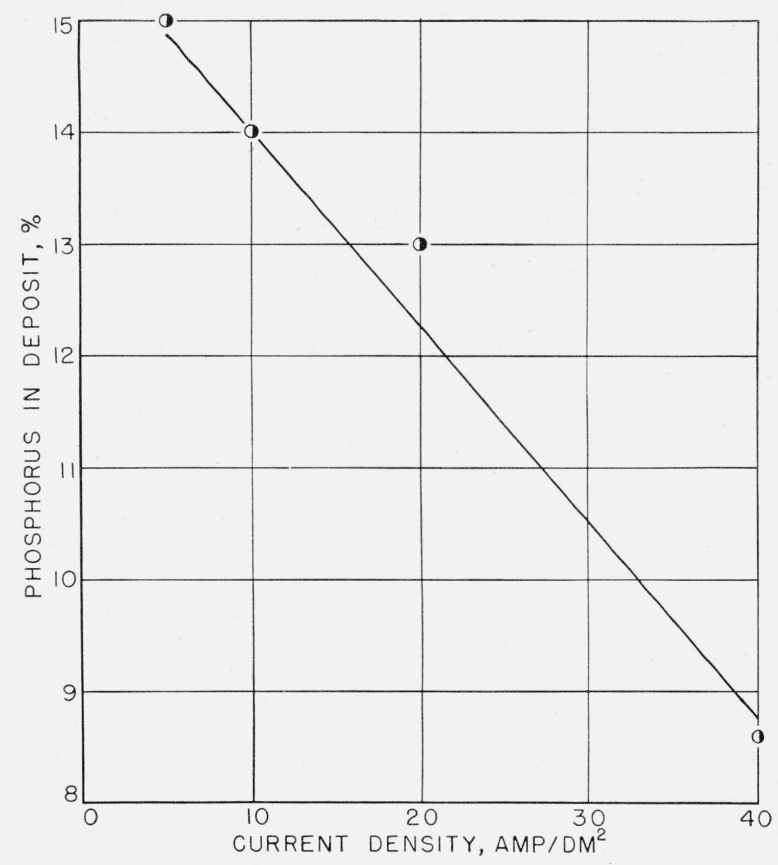

FIGURE 4. Effect of current density upon percentage of phosphorus in alloys deposited from $\mathrm{Ni}-\mathrm{H}$ bath.

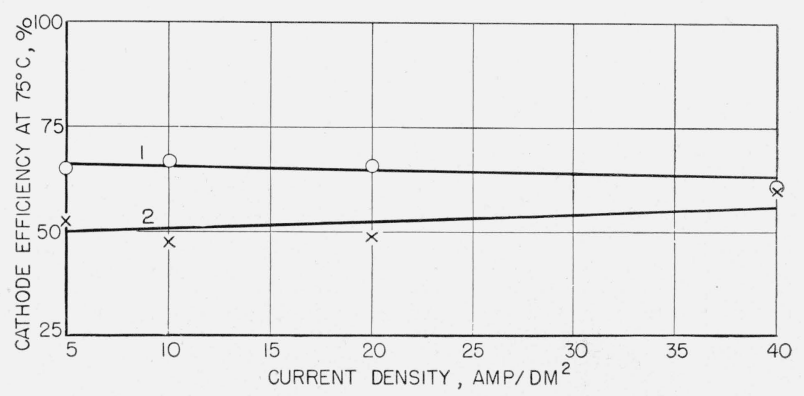

Figure 5. Effect of current density on cathode current efficiency of nickel-phosphorus baths operated at $75^{\circ} \mathrm{C}$. 1, Bath Ni-L; 2, bath Ni-H.

\section{Properties of the Deposits}

\section{Appearance}

The deposits varied in appearance, depending on their content of phosphorus. The deposits containing 2 percent or less of phosphorus were smooth and fine-grained but with a matte appearance very much like ordinary nickel or cobalt electrodeposits. Smooth deposits $8 \mathrm{~mm}$ (0.3 in.) thick were electroformed from the $\mathrm{Co}-\mathrm{F}$ bath without difficulty. Deposits with a phosphorus content of about 5 percent were semibright, and with a phosphorus content above 10 percent were 
fully bright. These were true bright deposits, because when formed on a dull surface they increased in brightness (although not in smoothness) with increase in thickness. The bright deposits had a slightly dark or yellowish cast, as might be expected from the fact that they contained a considerable amount of phosphide. Their reflectivity was about 45 to 50 percent as compared with 60 percent for nickel. The reflectivity of buffed deposits, which contained only 2 percent of phosphorus, was only slightly lower than the reflectivity of the pure metals.

\section{Hardness}

Interest in the hardness of the deposits gave the initial incentive for this study of the phosphorus alloys. The phosphorus-cobalt and -nickel alloys were harder than the pure metals. These alloys increased in hardness on heat treatment to an even larger extent than did the tungsten alloys of these metals [2]. The hardness of the phosphorus alloys, as deposited, ranged from about 350 to 700 Vickers. After heat treatment, the hardness of most of the deposits increased, with the maximum effect occurring at about $400^{\circ} \mathrm{C}$.

Figure 6 shows typical data for nickel- and cobalt-phosphorus deposits. The low phosphorusnickel deposits were harder than the corresponding cobalt deposits. Because the data for the nickel deposits cover a wider range of composition than for the cobalt deposits, more specific conclusions can be drawn regarding them. It is interesting to note that the hardnesses of the nickel deposits with from 2.5- to 13-percent phosphorus were about the same. The main effect of the larger contents of phosphorus was to cause the deposits to remain harder after being heat-treated at $800^{\circ} \mathrm{C}$.

The graph for the low phosphorus-cobalt deposits (curve 5, fig. 6) represents the average of about 15 deposits ranging in composition from 0.5 to 1.5-percent phosphorus. This curve represents within about 50 units the hardnesses of all of these samples. There were some minor variations in hardness depending on the bath and conditions of plating, but the data were not consistent enough to determine whether these differences were outside the limits of reproducibility. The main difference between the deposits containing 0.5 and 1.5 percent of phosphorus was that those with the higher phosphorus contents were harder after the heat treatment

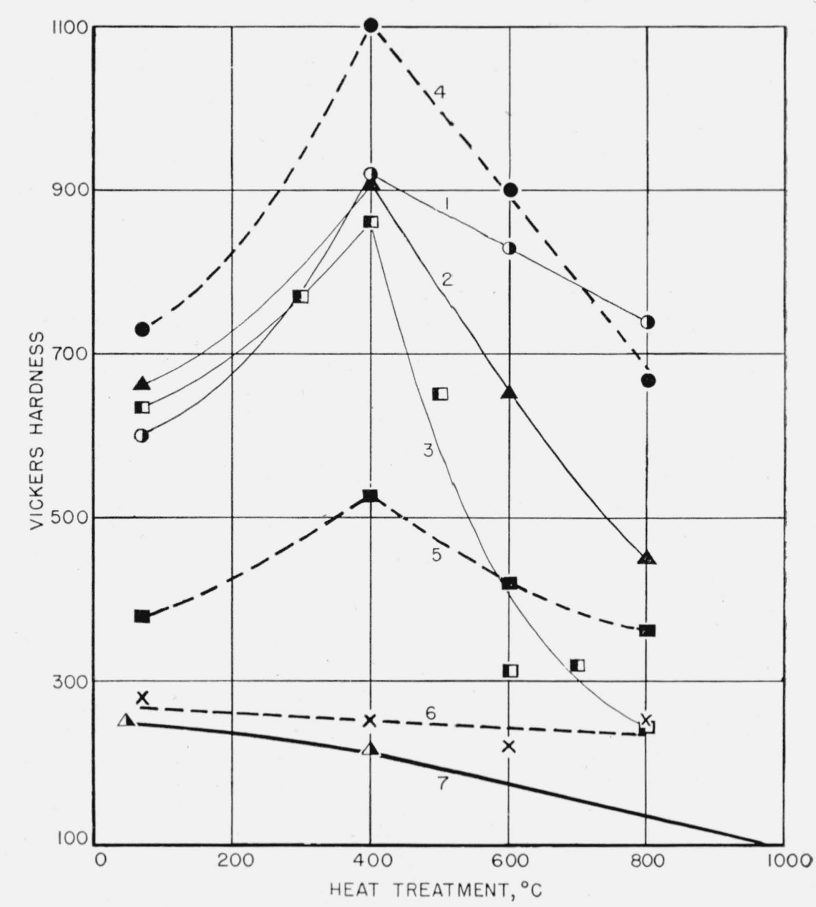

Figure 6. Effect of 1-hr heat treatment on the hardness of phosphorus-nickel and-cobalt alloys.

1, Bath Ni-H, 13 to $14 \%$ of phosphorus in deposit; 2, bath Ni-H, 6 to $7 \%$ of phosphorus in deposit; 3 , bath Ni-L, 2 to $3 \%$ of phosphorus in deposit; 4 , bath $\mathrm{Co}-\mathrm{H}, 10$ to $11 \%$ of phosphorus in deposit; 5 , bath Co-F, 0.5 to $1.5 \%$ of phosphorus in deposit; 6 , straight $\mathrm{CoCl}_{2}$ bath; 7 , straight $\mathrm{NiCl}_{2}$ bath.

at $800^{\circ} \mathrm{C}$ than the alloy as deposited. The high-phosphorus nickel and cobalt deposits became as hard as bright chromium after being heattreated at $500^{\circ} \mathrm{C}$. Heat treatment at higher temperatures $\left(800^{\circ} \mathrm{C}\right)$ does not soften the alloys as much as it does chromium. However, measurements of the hot-hardness of these alloys indicate that it was disappointingly low. The results are given in table 2 with cobalt as a basis of comparison.

TABLE 2. Hot hardness of phosphorus alloys of nickel and cobalt

\begin{tabular}{|c|c|c|c|c|c|c|c|}
\hline \multicolumn{3}{|c|}{ Deposit } & \multicolumn{5}{|c|}{ a Vickers Hardness Number at- } \\
\hline Metal & Bath & $\begin{array}{l}\text { Phos- } \\
\text { phorus }\end{array}$ & $25^{\circ} \mathrm{C}$ & $600^{\circ} \mathrm{C}$ & $800^{\circ} \mathrm{C}$ & $600^{\circ} \mathrm{C}$ & $25^{\circ} \mathrm{C}$ \\
\hline $\mathrm{Co}_{-.}$ & $\mathrm{Co}-\mathrm{L}$ & $\begin{array}{c}\text { Percent } \\
1.0\end{array}$ & 350 & 100 & 40 & 90 & 340 \\
\hline $\mathrm{Co}$ & $\mathrm{Co}-\mathrm{H}$ & 10 & 700 & 50 & $\ldots$ & 123 & 695 \\
\hline $\mathrm{Ni} \ldots \ldots$ & $\mathrm{Ni}-\mathrm{L}$ & 2.3 & 345 & 70 & 2 & 30 & -.. \\
\hline $\mathrm{Co} \ldots \ldots$ & (b) & -..- & 320 & 95 & 49 & $\ldots$ & 260 \\
\hline
\end{tabular}

a These hardnesses were taken in the order shown, that is, the second hardness at $600^{\circ} \mathrm{C}$ was taken after the sample had been heated to $800^{\circ} \mathrm{C}$, then cooled to $600^{\circ} \mathrm{C}$.

b Electrolytic cobalt deposited from a chloride bath. 


\section{Strength and Ductility}

The ductility of the deposits was examined qualitatively by determining whether they would bend or take a permanent deformation when a specimen in the form of a tube was crushed. The cobalt deposits containing up to 1 percent of phosphorus and nickel deposits containing up to 2 percent of phosphorus were strong and slightly ductile. The low phosphorus-cobalt deposits had a tensile strength of about $9,100 \mathrm{~kg} / \mathrm{cm}^{2}(130,000$ $\mathrm{lb} / \mathrm{in.}^{2}$ ) (as compared with about $5,300 \mathrm{~kg} / \mathrm{cm}^{2}$ $\left(75,000 \mathrm{lb} /\right.$ in. $\left.^{2}\right)$ for electrodeposited cobalt) and an elongation of about 7 percent. As the phosphorus content of the deposits increased, the deposits became brittle and somewhat weaker. After being heat-treated at $400^{\circ} \mathrm{C}$, which is the optimum hardening temperature, the cobaltand nickel-phosphorus alloys became more brittle. When they were heat-treated at $800^{\circ} \mathrm{C}$ the deposits with the lower phosphorus contents became more ductile than they were originally, whereas those with the higher phosphorus contents remained brittle. The high nickel-phosphorus alloys became quite weak after heating to $800^{\circ} \mathrm{C}$. One point that has not yet been settled is whether it is possible to heat-treat one of the alloys, for example, at $600^{\circ}$ or $800^{\circ} \mathrm{C}$, and to cause it to increase in both ductility and hardness.

\section{Density}

As shown in figure 7, the density of phosphorusnickel alloys decreases as the content of phosphorus in the deposit increases. The density of the deposits did not change appreciably as a result of heat treatment. Over the short range of composition shown, the relation between density and content of phosphorus is nearly linear, and the density-composition curve could be used to determine the composition of the deposit. The densities of several thermally prepared nickel phosphides are given in the literature $[3,4]: \mathrm{Ni}_{3} \mathrm{P}, 7.8$; $\mathrm{Ni}_{7} \mathrm{P}_{3}, 7.4 ; \mathrm{Ni}_{2} \mathrm{P}, 7.2 ; \mathrm{NiP}_{0.82}, 5.85$. With these values for density, the theoretical curves for density against composition have been calculated for the nickel-phosphorus alloy and are represented in the figure by the solid lines.

\section{Electrical and Magnetic Properties}

The presence of phosphorus in the alloy considerably increases its resistivity above that of

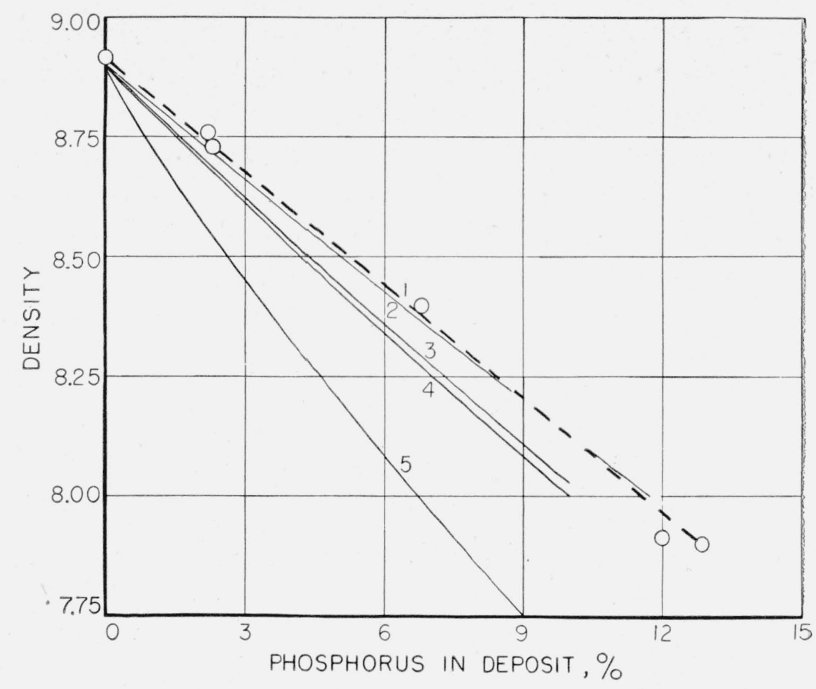

FiguRE 7. Effect of percentage of phosphorus on density of nickel-phosphorus alloys.

1, Experimental values; 2 , curve calculated for $\mathrm{Ni}_{3} \mathrm{P}$ plus $\mathrm{Ni}$; 3 , curve calculated for $\mathrm{Ni}_{7} \mathrm{P}_{3}$ plus $\mathrm{Ni}$; 4 , curve calculated for $\mathrm{Ni}_{2} \mathrm{P}$ plus $\mathrm{Ni} ; 5$, curve calculated for $\mathrm{NiP}_{0.82}$ plus $\mathrm{Ni}$.

the pure metal. On heat treating the deposits, the resistivity decreased to a minimum at $600^{\circ} \mathrm{C}$. These relations are shown in figure 8 .

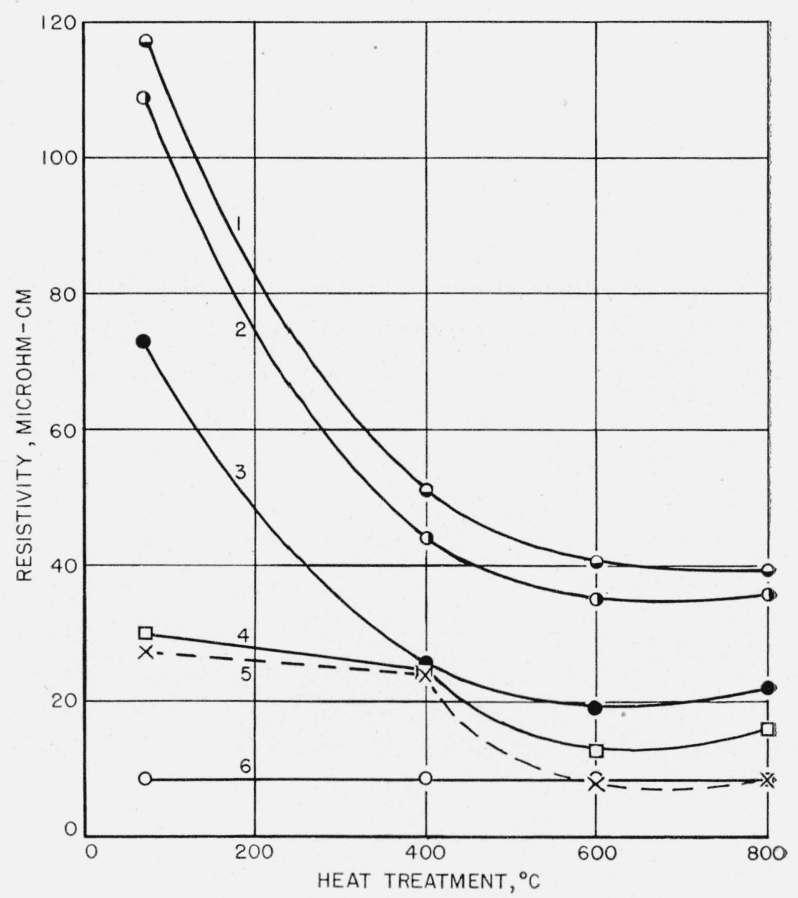

FIGURE 8. Variations of resistivity of phosphorus alloys caused by a 1-hr heat treatment.

1, Ni-H type bath, $13 \%$ of phosphorus; 2 , Ni-H type bath, $10 \%$ of phosphorus; 3 , Ni-H type bath, $7 \%$ of phosphorus; 4 , Ni-L type bath, $2.2 \%$ of phosphorus; 5 , Co-F type bath, $1.3 \%$ of phosphorus; 6 , similar to bath Ni-L, but containing no phosphorus acid. 
No measurements have been made of the magnetic properties of the phosphorus alloys beyond testing them with a magnet. Cobalt deposits containing up to 10 percent of phosphorus are magnetic. Nickel deposits are nonmagnetic, if they contain more than 8 percent of phosphorus.

\section{Stress in Deposits}

It was of interest to measure the stress in the cobalt-phosphorus deposits because one objective of this study was to electroform deposits about $1 \mathrm{~cm}$ thick. The stress in the cobalt-phosphorus deposits was compared with the stress in cobalt deposits. The latter will be discussed first.

The stress, measured with a spiral contractometer [5], in the deposit from a cobalt chloride bath varied with the $\mathrm{pH}$ and temperature of the bath and, in general, was a little lower than the stress. in nickel deposits obtained from an allchloride bath. The stress in cobalt deposited at a $\mathrm{pH}$ of 3 and at $75^{\circ} \mathrm{C}$ was about $1,800 \mathrm{~kg} / \mathrm{cm}^{2}$ $\left(26,000 \mathrm{lb} / \mathrm{in}^{2}{ }^{2}\right)$. The stress was highest in deposits made at a $\mathrm{pH}$ of 1 to 2 , and lowest at a $\mathrm{pH}$ of 5 . The stress in the cobalt deposits was not enough to crack deposits $1 \mathrm{~mm}$ thick, but occasionally deposits 5 to $8 \mathrm{~mm}$ thick would crack spontaneously. The explanation for this is not known.

The deposit from the Co-F cobalt bath had about the same stress as the deposit from a cobalt chloride bath, that is, about $1,800 \mathrm{~kg} / \mathrm{cm}^{2}(26,000$ $\mathrm{lb} / \mathrm{in}^{2}{ }^{2}$. On the addition of phosphorous acid to a concentration of about $2 \mathrm{~g} /$ liter, the stress increased to about $2,500 \mathrm{~kg} / \mathrm{cm}^{2}\left(36,000 \mathrm{lb} / \mathrm{in}^{2}{ }^{2}\right.$. This stress caused no difficulty in making deposits a millimeter thick, but in electroforming heavier deposits the coating would sometimes crack spontaneously. By adding several grams of saccharin per liter of the bath, the stress was reduced to about its original value. This effect of saccharin is not as pronounced in the cobaltphosphorus bath as in ordinary nickel baths, in which the stress can be reduced to zero or even be made of the opposite sign, that is, changed from a tensile to a compressive stress. Naphthalene trisulfonic acid, which is sometimes added to bright nickel baths to reduce stress, reduced the stress of the cobalt deposit by only about 20 percent. It may be used in conjunction with the saccharin, but it has not been determined whether it affords any significant improvement. Although the stress in the deposits formed at room temperature was not much higher than in those made at $75^{\circ} \mathrm{C}$, the former deposits tended to crack, probably because they were weaker and more brittle and hence could not withstand the stress developed in plating.

\section{Chemical Properties of the Phosphorus Alloys}

As cobalt and nickel phosphides that are prepared by thermal methods are not attacked by hydrochloric acid, it was expected that the phosphorus alloys would be less attacked by this acid than are the pure metals. This expectation was not entirely borne out (table 3 ), as the low phosphorus-cobalt and -nickel alloys (containing 1 to $2 \%$ of phosphorus) were attacked by hydrochloric acid more rapidly than were the pure metals. However, the high phosphorus-nickel alloy (containing $10 \%$ to $15 \%$ of phosphorus) was more resistant than pure nickel, and both the high phosphorus-cobalt and the high phosphorusnickel alloys were more resistant to attack by nitric acid than the pure metals.

In the salt spray test, the low phosphorus-cobalt alloy plated upon steel did not afford the steel as much protection as did pure cobalt coatings, and the nature of the corrosion was different. Rust spots formed on the cobalt-alloy coatings in the same manner that they form on standard nickel corrosion test samples and the deposits did not tarnish appreciably. Pure cobalt coatings, even if only $0.005 \mathrm{~mm}$ (0.0002 in.) thick, tarnished rapidly in the salt spray, forming a brown or dark purple film and no rust, or rust spots were formed. Bright nickel-phosphorus coatings (10 to $15 \%$ phosphorus) behaved in the salt spray very much like ordinary nickel coatings. After 2 days, thin deposits (several thousandths of a millimeter thick) had numerous rust spots, but a deposit about $0.035 \mathrm{~mm}(0.0014 \mathrm{in}$.) thick did not show any rust spots after two weeks.

The phosphorus alloys, particularly the high phosphorus-cobalt alloy, turned black when treated for less than a minute with an oxidizing acid such as nitric acid, or when it was made anodic in the bath. When the black coating was not made too thick, it was hard and durable, and it may have some decorative value as well as afford. ing protection against corrosion. 
TABLE 3. Rates of attack of cobalt, nickel, phosphorus cobalt, and phosphorus nickel by nitric and hydrochloric acids

\begin{tabular}{|c|c|c|c|}
\hline \multirow{2}{*}{ Metal } & \multicolumn{3}{|c|}{ Weight loss in $\mathrm{mg} / \mathrm{cm}^{2} \mathrm{hr}$} \\
\hline & As plated & $\begin{array}{l}\text { Heated to } \\
400^{\circ} \mathrm{C}\end{array}$ & $\begin{array}{l}\text { Heated to } \\
600^{\circ} \mathrm{C}\end{array}$ \\
\hline \multicolumn{4}{|c|}{ IN 1:1 HYDROCHLORIC ACID } \\
\hline $\mathrm{Co}_{\ldots} \ldots \ldots$ & 1.2 & & -..... \\
\hline $\mathrm{Co}+1 \% \mathrm{P}$ & 20.0 & 9.3 & 3.1 \\
\hline $\mathrm{Co}+10 \% \mathrm{P}_{-}$ & 4.6 & - n....... & 0.2 \\
\hline $\mathrm{Ni}$ & 0.2 & $-\cdots$ & $\ldots$ \\
\hline $\mathrm{Ni}+2 \% \mathrm{P} \ldots$ & 1.9 & 1.5 & 1.1 \\
\hline $\mathrm{Ni}+14 \% \mathrm{P} \ldots$ & 0.604 & & 0.003 \\
\hline \multicolumn{4}{|c|}{$\begin{array}{l}\text { IN AIR ABOVE CONCENTRATED HYDROCHLORIC } \\
\text { ACID }\end{array}$} \\
\hline $\mathrm{Co}$ & 0.03 & & \\
\hline $\mathrm{Co}+1 \% \mathrm{P}$ & (a) & & \\
\hline $\mathrm{Co}+10 \% \mathrm{P}$ & (a) & 0.5 & 0.1 \\
\hline $\mathrm{Ni} \ldots \ldots$ & 0.02 & & \\
\hline $\mathrm{Ni}+2 \% \mathrm{P} \ldots$ & 1.6 & & 1.3 \\
\hline $\mathrm{Ni}+14 \% \mathrm{P} \ldots$ & 0.004 & - n & 0.01 \\
\hline \multicolumn{4}{|c|}{ IN 1:1 NITRIC ACID } \\
\hline Co & $1,860.0$ & & \\
\hline $\mathrm{Co}+1 \% \mathrm{P}$ & 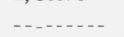 & & \\
\hline $\mathrm{Co}+10 \% \mathrm{P}$ & 960 & -......... & 600.0 \\
\hline $\mathrm{Ni}$ & 168.0 & -......... & - n....... \\
\hline $\mathrm{Ni}+2 \% \mathrm{P} \ldots$ & 234.0 & - n & 90.0 \\
\hline $\mathrm{Ni}+14 \% \mathrm{P} \ldots$ & 36.0 & -........ & .......... \\
\hline
\end{tabular}

a These react very rapidly and fell apart during the 16 -hr test run.

\section{Structure of Deposits}

\section{Microstructure}

Photomicrographs of nickel and cobalt deposits are shown in figures 9 and 10 . The low phosphorus-cobalt deposits, figure 9 , E, from bath Co-F show a columnar structure superimposed upon laminations parallel to the basis metal. The crystals seem to be more clearly defined and larger than those in ordinary cobalt deposits, figure $9, \mathrm{~A}$, which is somewhat surprising in view of the greater hardness of the deposits. Usually the grain structure of a metal becomes much finer when another element is codeposited with it. The structure developed depended upon the etching reagent used. Good results were obtained on cobalt-phosphorus with a mixture of phosphoric acid and hydrogen peroxide and also with a mixture of chromic and sulfuric acids. However, the commonly used nitric-acetic acid mixtures caused irregular pitting of the deposits.

The high-phosphorus nickel and cobalt deposits were more resistant to etching. Immersion in a mixture of nitric and hydrochloric acids or electrolysis as anode in nitric acid brought out the microstructure satisfactorily. The Ni-L and Ni-H deposits (figs. 10, C, and 10, E) showed only a laminated structure, which after heating to $800^{\circ}$ $\mathrm{C}$, went over to a very fine grain structure. The Co-H deposit, as plated (fig. 9, I), showed a laminated structure that appeared to be broken into a series of rectangles. These also were converted to a very fine grain structure by heating to $800^{\circ} \mathrm{C}$ (fig. 9, J).

\section{By X-ray Examination}

The structure of the nickel- and cobalt-phosphorus alloys was examined by X-ray diffraction by H. C. Vacher of the Metallurgy Division of this Bureau. A specimen of the low cobalt-phosphorus alloy, which contained 1 percent of phosphorus and therefore probably about 5 percent of the phosphide, showed only lines characteristic of cobalt. A specimen of the high nickel-phosphorus alloy yielded only one diffuse band, which indicated that the material was amorphous, and therefore no information could be obtained about its composition. On heat-treating the specimen at $800^{\circ} \mathrm{C}$, numerous lines appeared in addition to those of nickel, but it was not possible to determine whether these lines corresponded to any of the nickel phosphides that have been reported in the literature.

\section{By Chemical Examination}

An attempt was made to isolate the phosphide from the nickel deposits by direct solution in acid and by making the deposit anodic, but very little residue was left behind. A small amount of residue obtained from a cobalt specimen was found by analysis to be approximately $\mathrm{Co}_{3} \mathrm{P}_{2}$, but this may have been formed from a lower phosphide, by the action of the acid [6].

A number of phosphides of nickel and cobalt have been reported in the literature. The existence of three phosphides of cobalt, $\mathrm{Co}_{2} \mathrm{P}, \mathrm{CoP}$, and $\mathrm{CoP}_{3}$, have been definitely established [7], and several others have been described, $\mathrm{Co}_{3} \mathrm{P}_{2}$, $\mathrm{Co}_{4} \mathrm{P}_{3}$, and $\mathrm{Co}_{2} \mathrm{P}_{3}$. About seven nickel phosphides 
have been fairly well characterized in the literature: $\mathrm{Ni}_{3} \mathrm{P}, \mathrm{Ni}_{7} \mathrm{P}_{3}, \mathrm{Ni}_{5} \mathrm{P}_{2}, \mathrm{Ni}_{2} \mathrm{P}, \mathrm{NiP}_{0.821}, \mathrm{NiP}_{2}$, and $\mathrm{NiP}_{3},[3,4,6,8,9]$. The data in figure 7 on density would favor a compound having a phosphorus content corresponding to $\mathrm{Ni}_{3} \mathrm{P}$. This might also be $\mathrm{Ni}_{5} \mathrm{P}_{2}$, which has been isolated from nickel obtained by reduction with hypophosphite in aqueous solution $[6,9]$. On the basis of $\mathrm{Ni}_{5} \mathrm{P}_{2}$, a nickel-phosphorus alloy containing 15 percent of phosphorus would contain 85 percent of phosphide. On the basis of $\mathrm{Ni}_{3} \mathrm{P}$, the alloy would consist entirely of nickel phosphide.

The equilibrium diagram $[10,11]$ indicates that phosphorus is soluble in cobalt only to the extent of a few tenths of a percent. This would indicate that the phosphorus alloys may be unstable solid solutions or mixtures of individual particles of metal and metal phosphides. The former hypothesis is favored, since the hardening of the metals on heating and the development of particles on heating as shown by the photomicrographs would indicate the precipitation of a second phase that must have been in a metastable solution in the metal.

\section{Possible Applications}

The phosphorus-cobalt and -nickel deposits should be useful wherever hardness is required and could be considered as an alternative to chromium deposits. They would be particularly useful if the deposits are subjected to heat, as ordinary hard nickel will be permanently softened after heating to $600^{\circ} \mathrm{C}$, whereas the phosphorus alloys do not change appreciably in hardness.

The bright nickel-phosphorus coating could be used for protective or decorative plating, although it is not as white or as bright as commercial bright nickel. The phosphorus-nickel alloy can be chromium plated, but the finish is satin rather than bright. The bright nickel-phosphorus bath can be more easily controlled than other bright nickel baths because it contains no organic constituents, and the brightening agent, phosphite, is used in large quantity. The phosphorus-cobalt deposit might also be used for decorative finishes as it can be plated bright, but a more unusual use would be the production of the black deposits mentioned above.

The authors express their appreciation to Virginia D. Morgan for taking the many hardness measurements that were required.

\section{References}

[1] A. Brenner and G. Riddell, J. Research NBS 37, 31 (1946) RP1725; 39, 385 (1947) RP1835.

[2] A. Brenner, P. Burkhead, and E. Seegmiller, J. Research NBS 39, 351 (1947) RP1834.

[3] H. Nowotny and E. Henglein, Z. physik. Chem. 40B, 281 (1938).

[4] W. Biltz and M. Heimbrecht, Z. anorg. allgem. Chem. 23\%, 132 (1938).

[5] A. Brenner and S. Senderoff, J. Research NBS 42, 89 (1949) RP1953.

[6] R. Scholder and H. L. Haken, Ber. 64, (B. 2), 2870 (1931).

[7] W. Biltz and M. Heimbrecht, Z. anorg. Chem. 241, 349 (1939).

[8] N. Konstantinow, Z. anorg. Chem. 60, 405 (1908).

[9] R. Scholder and H. Heckel, Z. anorg. allgem. Chem. 198, 329 (1931).

[10] S. Zemczuzny and J. Schepelew, Z. anorg. Chem. 64, 245 (1909).

[11] U. Haschimoto, Nippon Kinzoku Gakukai-Shi 2, 72 (Feb. 1938).

Washington, August 19, 1949. 

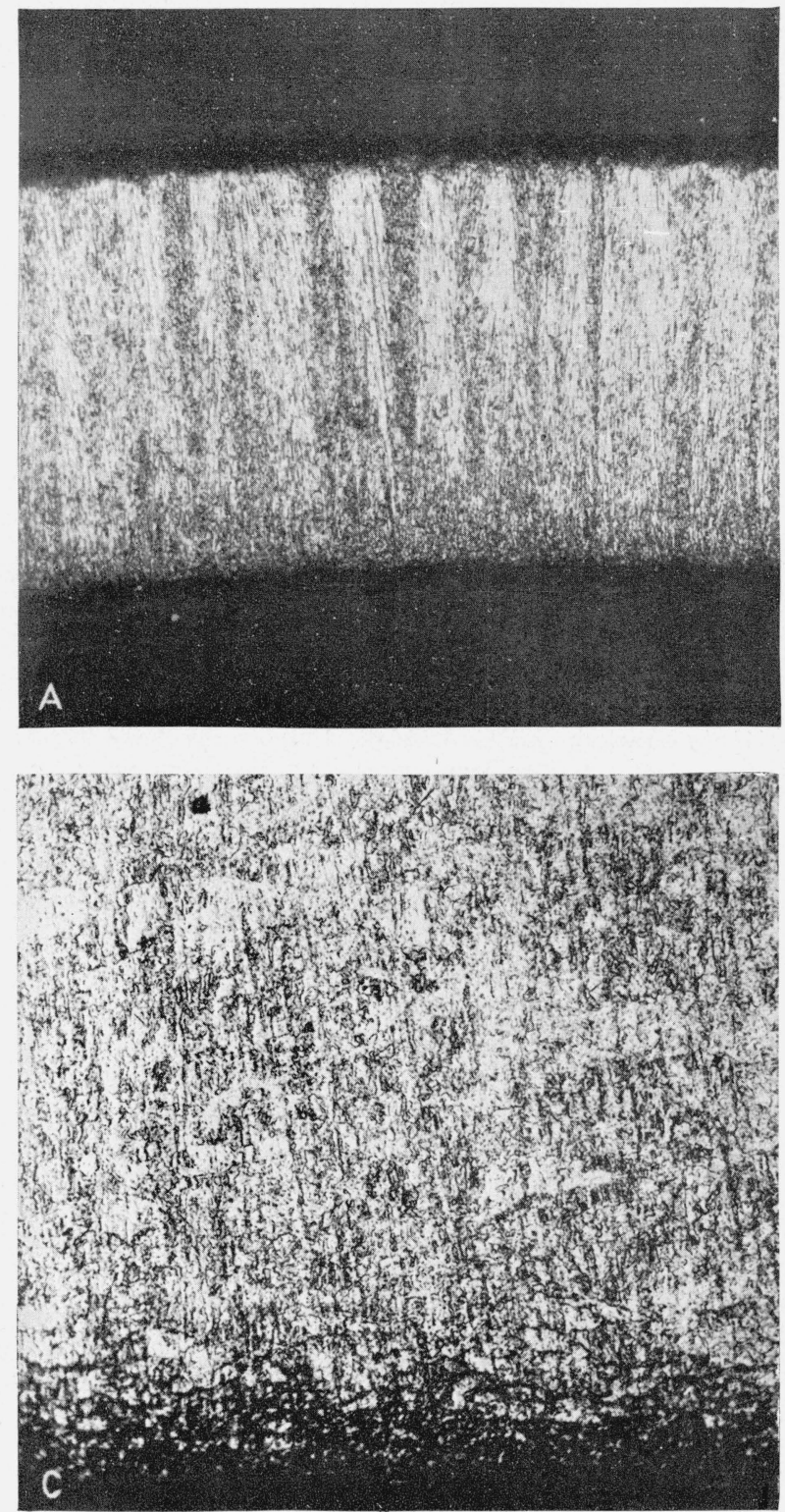
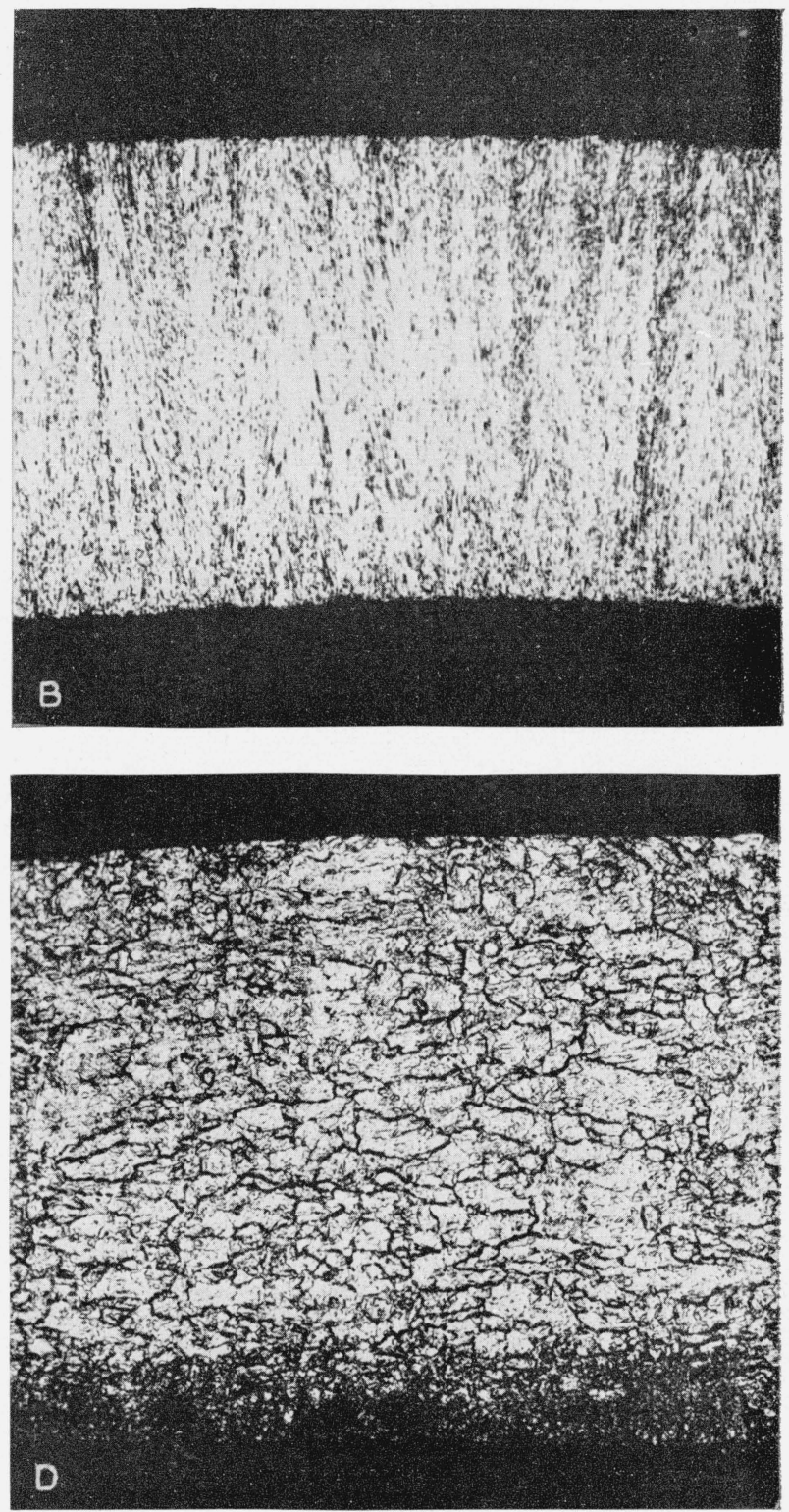

Figure 9. Photomicrographs of cobalt and phosphorus-cobalt alloys $\times 250$.

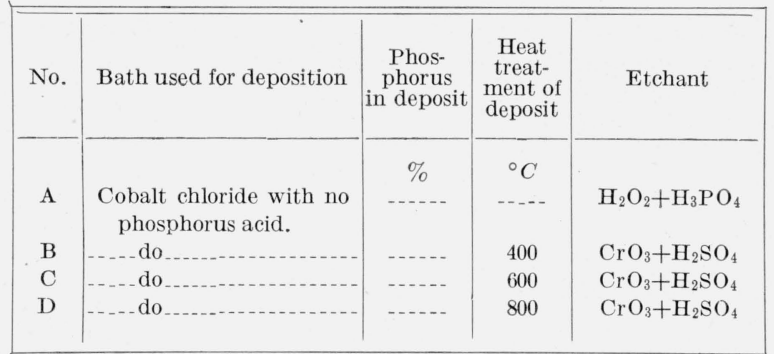



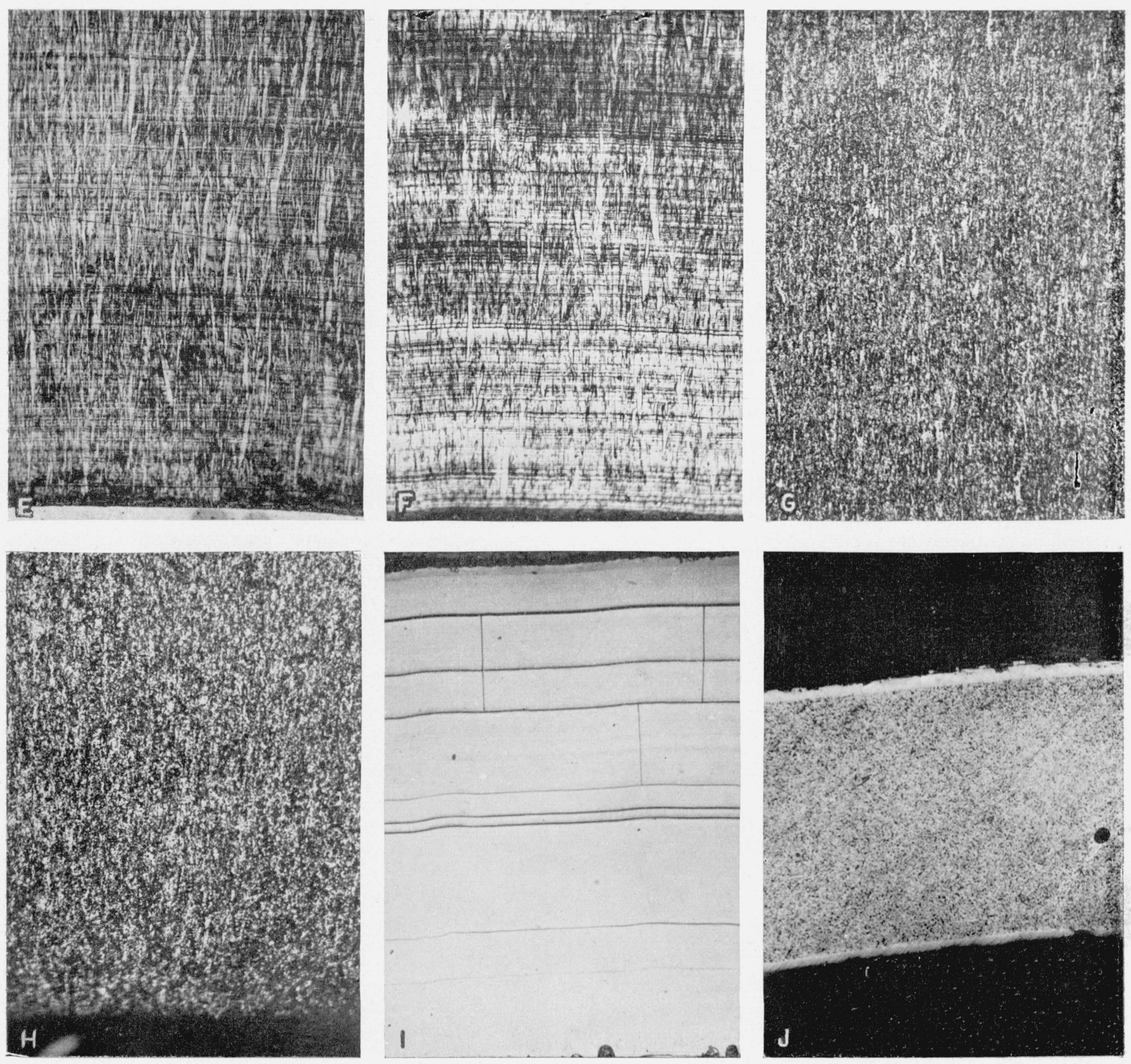

Figure 9 (continued). Photomicrographs of cobalt and phosphorus-cobalt alloys $\times 250$.

\begin{tabular}{|c|c|c|c|c|}
\hline No. & $\begin{array}{c}\text { Bath used } \\
\text { for deposition }\end{array}$ & $\begin{array}{l}\text { Phos- } \\
\text { phorus } \\
\text { deposit }\end{array}$ & $\begin{array}{l}\text { Heat } \\
\text { treat- } \\
\text { ment of } \\
\text { deposit }\end{array}$ & Etchant \\
\hline $\begin{array}{c}\mathrm{E} \\
\mathrm{F} \\
\mathrm{G} \\
\mathrm{H} \\
\mathrm{I}\end{array}$ & $\begin{array}{l}\mathrm{Co}-\mathrm{F} \\
\mathrm{Co}-\mathrm{F} \\
\mathrm{Co}-\mathrm{F} \\
\mathrm{Co}-\mathrm{F} \\
\mathrm{Co}-\mathrm{H}\end{array}$ & $\begin{array}{l}\% \\
2.2 \\
2.2 \\
2.2 \\
2.2 \\
10\end{array}$ & $\begin{array}{c}{ }^{\circ} \mathrm{C} \\
-400 \\
600 \\
800 \\
\\
\end{array}$ & $\begin{array}{c}\mathrm{CrO}_{3}+\mathrm{H}_{2} \mathrm{SO}_{4} \\
\mathrm{CrO}_{3}+\mathrm{H}_{2} \mathrm{SO}_{4} \\
\mathrm{CrO}_{3}+\mathrm{H}_{2} \mathrm{SO}_{4} \\
\mathrm{CrO}_{3}+\mathrm{H}_{2} \mathrm{SO}_{4} \\
\text { Electrolytic } \\
\mathrm{HNO}_{3}+\mathrm{H}_{3} \mathrm{COOH} \\
\text { Electrolytic } \\
\mathrm{HNO}_{3}+\mathrm{CH}_{3} \mathrm{COOH}\end{array}$ \\
\hline
\end{tabular}



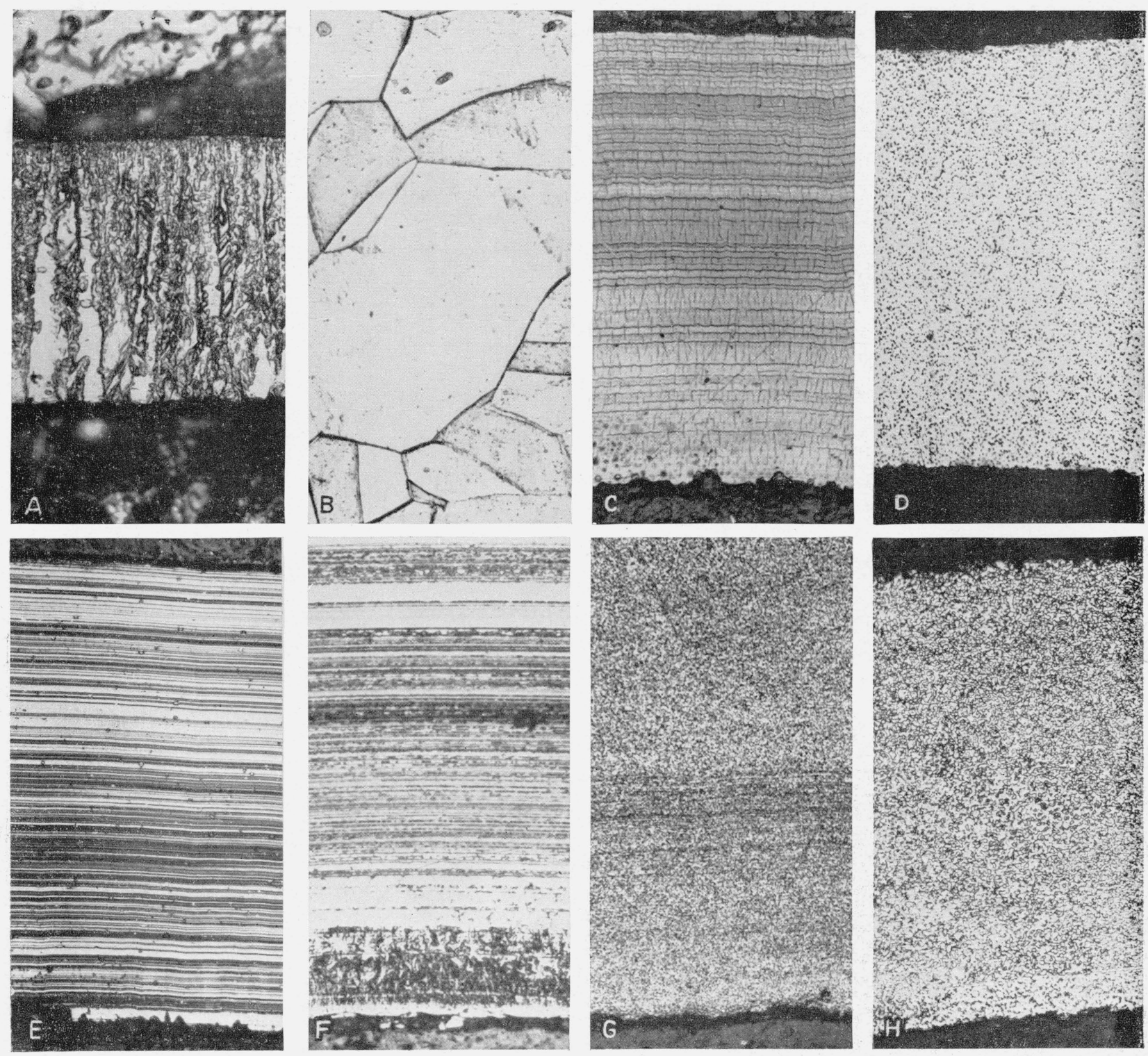

Figure 10. Photomicrographs of nickel and phosphorus-nickel alloys $\times 250$.

\begin{tabular}{|c|c|c|c|c|}
\hline No. & $\begin{array}{l}\text { Bath used } \\
\text { for deposition }\end{array}$ & $\begin{array}{c}\text { Phos- } \\
\text { phorus } \\
\text { in deposit }\end{array}$ & $\begin{array}{l}\text { Heat } \\
\text { treat- } \\
\text { ment of } \\
\text { deposit }\end{array}$ & Etchant \\
\hline & & $\%$ & ${ }^{\circ} \mathrm{C}$ & \\
\hline $\begin{array}{l}\text { A } \\
\text { B }\end{array}$ & $\begin{array}{l}\text { Watts } \\
\text { Watts }\end{array}$ & (n.... & 1,000 & $\begin{array}{l}\mathrm{HNO}_{3}+\mathrm{CH}_{3} \mathrm{COOH} \\
\mathrm{HNO}_{3}+\mathrm{CH}_{3} \mathrm{COOH}\end{array}$ \\
\hline $\mathrm{C}$ & $\mathrm{Ni}-\bar{L}$ & 2.3 & ....... & Aqua regia \\
\hline $\mathrm{D}$ & $\mathrm{Ni}-\mathrm{L}$ & 2.3 & 800 & $\begin{array}{c}\text { Electrolytic, } \\
\mathrm{HNO}_{3}+\mathrm{CH}_{3} \mathrm{COOH}\end{array}$ \\
\hline $\mathrm{E}$ & $\mathrm{Ni}-\mathrm{H}$ & 13 & $\cdots$ & $\begin{array}{c}\text { Electrolytic, } \\
\mathrm{HNO}_{3}+\mathrm{CH}_{3} \mathrm{COOH}\end{array}$ \\
\hline $\mathrm{F}$ & $\mathrm{Ni}-\mathrm{H}$ & 13 & 400 & $\begin{array}{c}\text { Electrolytic, } \\
\mathrm{HNO}_{3}+\mathrm{CH}_{3} \mathrm{COOH}\end{array}$ \\
\hline G & $\mathrm{Ni}-\mathrm{H}$ & 13 & 600 & $\begin{array}{c}\text { Electrolytic, } \\
\mathrm{HNO}_{3}+\mathrm{CH}_{3} \mathrm{COOH}\end{array}$ \\
\hline $\mathrm{H}$ & $\mathrm{Ni}-\mathrm{H}$ & 13 & 800 & $\begin{array}{c}\text { Electrolytic, } \\
\mathrm{HNO}_{3}+\mathrm{CH}_{3} \mathrm{COOH}\end{array}$ \\
\hline
\end{tabular}

○ 